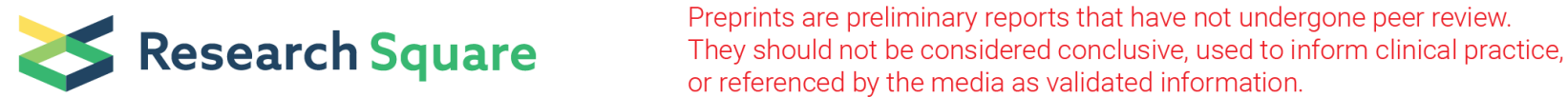

\section{Effect of short-term educational intervention on complementary feeding index among infants in rural Bangladesh: a randomized control trial}

\author{
Aminur Rahman ( $\nabla$ draminur@icddrb.org) \\ International Centre for Diarrhoeal Disease Research \\ Badrul Bhuiyan \\ Liverpool John Moores University \\ Sumon Kumar Das \\ Menzies School of Health Research
}

\section{Research Article}

Keywords: Infants, stunting, underweight, malnutrition, CF, infant feeding, rural, Bangladesh.

Posted Date: January 31st, 2022

DOI: https://doi.org/10.21203/rs.3.rs-1193991/v1

License: (c) (i) This work is licensed under a Creative Commons Attribution 4.0 International License. Read Full License 


\section{Abstract}

Background:Timely, adequate and appropriate CF is essential for the growth and cognitive development of infants, but until today, evidence-based information is scarce in terms of impact evaluation of CF index (CFI). The study aimed to examine the effect of the short-term intervention of promoting CFCF practices on the nutritional status of infants in rural Bangladesh.

Methods: An educational-intervention study followed a randomized controlled trial (RCT) design (NCT03024710). Mothers and family members in the intervention arm received intensive counselling on CFCF through community health workers (CHWs), whereas existing healthcare services were received in the comparison arm. The study was carried out in the rural Matlab sub-district of Bangladesh between April 2011 and March 2013. In the specified study areas among 360 mother-infant pairs systematically assigned into intervention group and comparison group. Short-term educational intervention on CF was provided for the intervention group and existing services were un-intervened for the comparison group. The outcome of interventions was evaluated after the implementation period using Generalized equation estimation model.

Results: At baseline, the study participants were not different except mean height, weight-for-age Z score (WAZ) and religion in between two groups. The mean CFI was significantly higher at intervention area than the comparison and higher category of $\mathrm{CFI}$ (score 10 or more) was significantly higher at intervention area than comparison. After adjustment, one-unit $\mathrm{CFI}$ increased height-for-age $z$ score by 0.07 units and decreased WAZ by 0.13 units in the intervention group but not significantly changed observed at comparison group.

Conclusion: Guided short-term nutritional intervention and developed CFI indicated a significantly better score in intervention area than comparison groups and would be a well adaptable tool for future studies.

\section{Trial registration:}

The trial was registered (NCT03024710) at clinical trial registration website. Date of registration: 1/19/2017

\section{Name of the registry:}

Clinical Trial.gov

\section{Date of registration:}

19/1/2017 (retrospective registered)

\section{URL of trial:}

https://clinicaltrials.gov/ct2/show/NCT03024710

\section{Background}

Globally 165 million under-five children have chronic undernutrition and $90 \%$ of them live in only 36 countries (1). Poor nutrition increases the risk of childhood morbidity, responsible for one-third of the deaths in children less than five years of age (1). The benefits of breastfeeding and optimal complementary feeding (CF) for child survival, growth and development have been well documented through research $(2,3)$. CF for infants (at about six months of age) refers to the introduction of safe and nutritional foods in addition to breastfeeding (4). According to the World Health Organization (WHO), CF should be given timely, adequately, appropriately and in sufficient quantity (4). The period of CF (from 6 to 24 months) is one of the most critical times for preventing malnutrition $(5,6)$. Growth faltering is most evident during this period and it is extremely difficult to reverse the effects of stunting and some other functional deficits $(7,8)$. Universal coverage of exclusive breastfeeding could prevent $13 \%$ of child deaths globally, while appropriate CF practices added $6 \%$ reduction in under-five year mortality (9). However, lack of efforts is observed to increase the knowledge of good CF practices at the community level in developing countries including Bangladesh. 
Inappropriate practices of CF reflect the knowledge gap at the population level that induces undernutrition(10). Thus, a comprehensive programme of integrated actions on many fronts has been addressed, including promoting improved infant and young child feeding (IYCF) practices. At the community level, mothers and families (along with support persons or peer groups) need support to initiate and sustain appropriate IYCF practices(11). In a different context, educational intervention on CF practices showed notable nutritional improvement (12-14). However, they differ from exclusive breastfeeding (EBF) duration and starting of CF practices as recommended by WHO (15); and none of them evaluated feeding practices through $\mathrm{CF}$ index (CFI). CFI is a composite score that reflects the quality of implementing any nutritional intervention and helps to identify which varieties of recommended meal/s is/are not taken by the infants or the children. A few studies in Bangladesh assessed CFI utilizing Bangladesh Demographic and Health Survey (BDHS) or other national surveys (16-18) but very few of them followed the WHO guidelines on IYCF using six standard variables to measure the CFI (15). Recently, a few crosssectional studies determined the association of CFI with childhood undernutrition; but the determinants mostly remained unpredictable, mainly due to the lack of strong study design such as randomized control trial $(R C T)(19,20)$. In this context, the present community-based RCT was carried out to examine the effect of short-term intervention of CF promotion (through $\mathrm{CFI}$ ) on nutritional status of infants in rural Bangladesh.

\section{Methods}

\section{Study site and participants}

The study was conducted in the rural community of Matlab sub-district, Chandpur, Bangladesh, located 56 kilometers southeast of Dhaka, the capital city of Bangladesh. The International Centre for Diarrhoeal Disease Research, Bangladesh (icddr,b) has been conducting a Health and Demographic Surveillance System (HDSS) in a population of about 220,000 since 1966. At Matlab, a comprehensive maternal, neonatal \& child health (MNCH) programme was initiated in March 2007. Under this programme, all pregnancies in the area are being identified and followed-up bi-monthly at the household level. In addition, two additional visits are also being done (at 12-14 weeks and at 33-34 weeks of pregnancy) and counselling are also being provided to the mothers about facility-based delivery, antenatal care, and birth preparedness (21). For the present study, infants who completed six months of age were selected along with their mothers from the MNCH database. This database was upgraded bi-weekly basis after receiving information from Community Health Research Worker (CHRWs) and crosschecked by the field supervisors.

\section{Study design and randomization}

The study followed a RCT design. The MNCH programme area was divided into four blocks and each one comprises of an approximate 27,000 population (18). An independent researcher (who was not involved in the study in any way) paired the blocks into two, where each pair was assigned randomly into two groups: (i) intervention group and (ii) comparison group. To avoid information contamination, four blocks were paired into A, B and C, D according to the geographical location. Block C and $D$ were selected as intervention, and $A$ and $B$ were comprised as comparison areas.

\section{Sample size and enrolment}

The required sample was calculated based on earlier studies (17). Assuming the intervention effect could reduce stunting at $20 \%$ with available $41 \%$ of prevalence(22). With $5 \%$ significance level and $80 \%$ power, a design effect of 1.5 and a maximum of $30 \%$ dropout, the expected sample size would be 180 infant-mother pairs in each arm (Figure 3).

\section{Intervention}

At six months, all enrolled children and their mothers (around 180 child-mother pair) and a close companion were invited to the sub-centre for a session to deliver as set of standard information. These were: washing hands every time before preparing a meal for the infant, frequency of meal according to the age, the quantity of meal according to the age, consistency of meal, diversity of food for every day and responsive feeding. The Principal Investigator (PI) took one and half hours. After the end of the sharing information, the CHRWs measured the anthropometric indices (weight and height) following standard 
measuring tools and procedure in presence of PI and study supervisor. Similar sessions refreshers were repeated at nine months. In addition, the CHRWS visited at every selected child-home during eight, 10 and 12 months and delivered similar information and took the anthropometric measurements and recorded accordingly. Variables considered under CFI measure has been discussed in Table:1.

\section{Implementation}

Mothers and infants of completed six months were identified from the MNCH database for both areas between March 2011 and June 2011 randomly. At the beginning, baseline information was collected for each participant. If an infant was not present during initial household visit a schedule reattempted was carried on. Infant with severe illnesses or handicaps affecting development, feeding, or activity and absent during enrolment were excluded. The details of the enrolment have been described in Figure-1 (Trial profile).

All enrolled mothers along with other family members received two training (at enrollment and at nine months) on standard $\mathrm{CF}$ practices at designated sub-center health facilities for the intervention area. A training manual was developed following WHO and Bangladesh Breast Feeding Foundation guidelines.

\section{Ethical Approval}

An institutional review board (IRB) of icddr,b reviewed the protocol and provided approval. The protocol was registered (NCT03024710) at the clinical trial registration website.

\section{Data collection and quality control}

Trained community health research workers (CHRW), Field Research Assistants (FRAs) and Field Research Supervisors (FRSs) were assigned to monitor all the study activities. Children's weight and length (both intervention and comparison groups) were measured during enrolment at 6th, 8th, 9th, 10th and 12th months of age following standardized methods and their weight-for-age (WAZ; underweight <-2SD), height-for-age (HAZ; stunting <-2SD) and weight-for-height (WAZ; wasting $<-2 S D$ ) were estimated following standard method and by WHO-Anthro 2005 software. The Field Research Assistants (FRAs) and Field Research Supervisors (FRSs) received training on study questionnaires and anthropometric measurements. The FRAs were responsible for all supervision and monitoring for data collection. Day to day supervision and monitoring was carried by the FRSs using the SOP checklist. Any inconsistency or queries were re-assessed upon discussing with the respective $\mathrm{CHRW}$ and FRA. For quality control, $5 \%$ participants were randomly chosen and were re-interviewed by the trained FRAs within two weeks after routine interview.

Table:1 Variables consider under Dependent and Independent variables 


\begin{tabular}{|ll|}
\hline Dependent & Independent \\
\hline HAZ (Height-for-age Z score) & Mother Age \\
\hline WAZ (Weight-for-age Z score) & Education \\
\hline WHZ (Weight-for-height Z score) & \\
\hline Stunting (HAZ <-2SD) & Birth order \\
\hline Underweight (WAZ <-2SD) & Child sex \\
Wasting (WHZ <-2SD) & Socio-economic status \\
\hline CF Index (variables) & Religion \\
\hline - Breastfeeding & \\
\hline - Bottle feeding & \\
\hline - Initiation of CF & \\
\hline - Dietary diversity (last 24 hours) & \\
\hline - Food group frequency (Past 7 days) & \\
\hline - Meal frequency (last 24 hours) & \\
\hline
\end{tabular}

\section{Complementary feeding index score}

Table-2 describes the scoring pattern of six variables for CF (CF) practices of infants aged 6-12 months, such as continued breastfeeding, avoiding bottle feeding, timely initiation of CF, dietary diversity (past 24-hours), food group frequency, meal frequency (past 24-hours). The following seven food groups were consumed: starch staple (rice, kichuri, potato, roti, suzi etc.), pulses, milk (other than breast milk), meat/eggs, vit-A rich fruit, vegetables, other fruits and vegetables and others.

The dietary diversity (last 24 hours), food group frequency (Past 7 days), meal frequency (last 24 hours) were categorized and scored following ICFI guideline(23). The detail scorning for each ICFI items was given under Table 4.

Theoretically, the CFI score ranges from 3 to 11 (Table-2). For analysis we combined the two age-groups and grouped into terciles to form 3 categories of CF practices- low (7 or below), medium (8-9), and high (10 or above).

Table-2: Variables and scoring system used to construct the ICFI 


\begin{tabular}{|c|c|c|}
\hline Variables & 6-8 months & 9-12 months \\
\hline Breastfeeding & $\mathrm{No}=0, \mathrm{Yes}=2$ & $\mathrm{No}=0, \mathrm{Yes}=2$ \\
\hline Bottle feeding & $\mathrm{No}=0, \mathrm{Yes}=1$ & $\mathrm{No}=0, \mathrm{Yes}=1$ \\
\hline Initiation of CF & No=0, Yes=2 & $\mathrm{No}=0, \mathrm{Yes}=2$ \\
\hline $\begin{array}{l}\text { Dietary diversity (last } \\
24 \text { hours) }\end{array}$ & $\begin{array}{l}\text { Low (no diversity) }=0, \text { Medium }(1-2 \\
\text { diversity) }=1 \text {, High ( } \geq 3 \text { diversity) }=2\end{array}$ & $\begin{array}{l}\text { Low (no diversity) }=0, \text { Medium }(1-3 \\
\text { diversity) }=1 \text {, High ( } \geq 4 \text { diversity) }=2\end{array}$ \\
\hline \multirow{2}{*}{$\begin{array}{l}\text { Food group frequency } \\
\text { (past } 7 \text { days) }\end{array}$} & Nil=0, 1-2 food group =1, & Nil=0, 1-3 food group $=1$, \\
\hline & $\geq 3$ food group $=2$ & $\geq 4$ food group $=2$ \\
\hline $\begin{array}{l}\text { Meal frequency (last } \\
24 \text { hours) }\end{array}$ & $\begin{array}{l}\text { No meal was given }=0, \text { Only single meal } \\
\text { given }=1, \geq 2 \text { meals given }=2\end{array}$ & $\begin{array}{l}\text { No meal was given }=0,1-2 \text { meals given }=1, \\
\geq 3 \text { meals given }=2\end{array}$ \\
\hline $\begin{array}{l}\text { Total maximum CFI } \\
\text { score }\end{array}$ & 11 & 11 \\
\hline
\end{tabular}

\section{Co-variates}

Several maternal socio-demographic data were collected. Such as asset quintile (poor, middle, rich); education of the mother (collected from HDSS database), age of the mother (calculated from the date of birth to the date of entry in study and grouped a $<20$ years, 20-24 years, 25-29 years, $\geq 30$ years); religion (Muslim and others); sex of the infant; education of the mother [no education, up to primary (1-5 class), up to secondary (6-10 class) and above secondary ( $\geq 11$ class)]; birth order (1, 2-3 and $\geq 4$ ). To estimate asset quintile assets included durable goods (e.g., table, chair, watch, television, or bicycle), housing facilities (e.g., type of toilet, or source of drinking water), housing materials (e.g., type of wall or roof), and possession of farming land.

\section{Analysis plan and outcome measures}

Baseline characteristics of the two groups were examined at enrollment. A Chi-square and t-test were performed to observe any association between the groups for categorical and continuous data, respectively. A p-value of $<0.05$ was considered significant. The primary outcome measure was to assess the change in all CFI indices in three time points at baseline (6 months), mid-time point ( 9 months) and at endline (12 months). The secondary outcomes were to assess the impact of CFI score (exposure) in changes in three nutritional outcomes (HAZ, WAZ and WHZ) over time. A Generalized Estimating Equation (GEE) was used separately for their nutritional indices for intervention and control group I (24). We considered three separate models to understand the potential confounding and modifying effect. Model 1 only CFl; model 2=Model-1 with child age and sex; and Model-3=Model-2 with maternal education, and asset score and religion.

Data cleaning was carried out by Statistical package for Social Sciences (SPSS, version 19) and per-protocol analyses were performed using stata (version 13).

\section{Results}

Detailed baseline characteristics of study participants were presented under Table 3 and found similar characteristics between the intervention and comparison groups (Table-3). Mother's education, religion and child's height and HAZ were found comparable between two groups at baseline. Significantly higher proportion of mothers in the intervention group had 
no education than the control group, majority of mothers from both intervention and control had secondary education. More than $80 \%$ of the study mothers were Muslim. On average, children from intervention and control groups had $65 \mathrm{~cm}$ height during baseline and mean HAZ was higher in the intervention than the control group.

Table-3: Baseline characteristics of the study participants at enrolment 


\begin{tabular}{|c|c|c|c|}
\hline \multirow[t]{2}{*}{ Indicators } & Intervention $(\mathrm{N}=180)$ & Control $(\mathrm{N}=180)$ & \multirow[t]{2}{*}{ p-value/t-test } \\
\hline & n $(\%) /$ mean $( \pm S D)$ & $\mathrm{n}(\%) /$ mean $( \pm \mathrm{SD})$ & \\
\hline \multicolumn{4}{|l|}{ Mother characteristics } \\
\hline Age & $26.9( \pm 0.5)$ & $27.2( \pm 0.5)$ & 0.74 \\
\hline$<20$ years & $14(7.8)$ & $8(4.4)$ & \multirow[t]{4}{*}{0.56} \\
\hline 20-24 years & $61(33.9)$ & $53(29.4)$ & \\
\hline $25-29$ years & $51(28.3)$ & $43(23.9)$ & \\
\hline$\geq 30$ years & $49(27.2)$ & $53(29.4)$ & \\
\hline \multicolumn{4}{|l|}{ Education } \\
\hline No education & $19(10.6)$ & $6(3.3)$ & \multirow[t]{4}{*}{0.05} \\
\hline Up to primary (1-5 class) & $52(28.9)$ & $52(28.9)$ & \\
\hline Up to secondary (6-10 class) & $101(56.1)$ & $108(60.0)$ & \\
\hline Above secondary ( $\geq 11$ class) & $8(4.4)$ & $14(7.8)$ & \\
\hline \multicolumn{4}{|l|}{ Birth order } \\
\hline 1 & $67(37.2)$ & $68(37.8)$ & \multirow[t]{3}{*}{0.86} \\
\hline $2-3$ & $93(51.7)$ & $89(49.4)$ & \\
\hline$\geq 4$ & $20(11.1)$ & $23(12.8)$ & \\
\hline \multicolumn{4}{|l|}{ Child characteristics } \\
\hline \multicolumn{4}{|l|}{ Sex } \\
\hline Male & $84(46.7)$ & $91(50.6)$ & \multirow[t]{2}{*}{0.46} \\
\hline Female & $96(53.3)$ & $89(49.4)$ & \\
\hline Height & $65.6( \pm 0.2)$ & $65.0( \pm 0.2)$ & 0.04 \\
\hline Weight & $7.04( \pm 0.1)$ & $7.01( \pm 0.1)$ & 0.72 \\
\hline Height for age z-score & $-0.48( \pm 0.1)$ & $-0.78( \pm 0.1)$ & 0.03 \\
\hline Weight for age z-score & $-0.72( \pm 0.1)$ & $-0.79( \pm 0.1)$ & 0.56 \\
\hline Height for weight z-score & $-0.46( \pm 0.1)$ & $-0.31( \pm 0.1)$ & -0.23 \\
\hline \multicolumn{4}{|l|}{ Household information } \\
\hline \multicolumn{4}{|l|}{ Socioeconomic status } \\
\hline Poor & $59(32.8)$ & $60(33.3)$ & 0.97 \\
\hline Middle & $36(20.0)$ & $34(18.9)$ & \\
\hline Rich & $85(47.2)$ & $86(47.8)$ & \\
\hline \multicolumn{4}{|l|}{ Religion } \\
\hline Muslim & 147 (81.7) & $161(89.4)$ & 0.04 \\
\hline Others & $33(18.3)$ & $19(10.6)$ & \\
\hline
\end{tabular}


SD: standard deviation

The proportion of stunting and wasting were persistently lower in the intervention than control group at all assessment time points. But there were no differences observed in wasting.

Table-4: Distribution of Infant Complimentary Feeding Index indicators 


\begin{tabular}{|c|c|c|c|c|c|c|c|c|c|}
\hline & \multicolumn{3}{|c|}{ Six months (Baseline) } & \multicolumn{3}{|l|}{ Nine months } & \multicolumn{3}{|c|}{ Twelve months (Endline) } \\
\hline & $\begin{array}{l}\text { Intervention } \\
(\mathrm{n}=180)\end{array}$ & $\begin{array}{l}\text { Control } \\
(n=180)\end{array}$ & $\begin{array}{l}\mathrm{p}- \\
\text { value }\end{array}$ & $\begin{array}{l}\text { Intervention } \\
(n=173)\end{array}$ & $\begin{array}{l}\text { Control } \\
(n=149)\end{array}$ & $\begin{array}{l}\mathrm{p}- \\
\text { value }\end{array}$ & $\begin{array}{l}\text { Intervention } \\
(n=160)\end{array}$ & $\begin{array}{l}\text { Control } \\
(n=165)\end{array}$ & $\begin{array}{l}\mathrm{p}- \\
\text { value }\end{array}$ \\
\hline $\begin{array}{l}\text { Continued } \\
\text { breastfeeding }\end{array}$ & $180(100)$ & $\begin{array}{l}177 \\
(98.3)\end{array}$ & 0.08 & $173(100)$ & $\begin{array}{l}146 \\
(97.9)\end{array}$ & 0.06 & $160(100)$ & $\begin{array}{l}161 \\
(97.6)\end{array}$ & 0.05 \\
\hline $\begin{array}{l}\text { Not Bottle } \\
\text { feeding }\end{array}$ & $150(83.3)$ & $\begin{array}{l}130 \\
(72.2)\end{array}$ & 0.01 & $156(90.2)$ & $\begin{array}{l}117 \\
(79.1)\end{array}$ & 0.01 & $146(91.3)$ & $\begin{array}{l}132 \\
(80)\end{array}$ & 0.00 \\
\hline $\begin{array}{l}\text { Initiation of } \\
\text { complementary } \\
\text { feeding }\end{array}$ & $160(88.9)$ & $\begin{array}{l}152 \\
(84.4)\end{array}$ & 0.17 & & & & & & \\
\hline \multicolumn{10}{|l|}{$\begin{array}{l}\text { Dietary } \\
\text { diversity (past } \\
24 \text { hours) }\end{array}$} \\
\hline $\begin{array}{l}\text { Low (no } \\
\text { diversity) }\end{array}$ & $21(11.7)$ & $\begin{array}{l}29 \\
(16.1)\end{array}$ & 0.46 & $2(1.2)$ & $1(0.7)$ & 0.00 & $0(0)$ & $1(0.6)$ & 0.00 \\
\hline $\begin{array}{l}\text { Medium (1- } \\
2 / 1-3^{*} \\
\text { diversity) }\end{array}$ & $103(57.2)$ & $\begin{array}{l}100 \\
(55.6)\end{array}$ & & $45(26)$ & $\begin{array}{l}86 \\
(57.7)\end{array}$ & & $50(31.25)$ & $\begin{array}{l}83 \\
(50.3)\end{array}$ & \\
\hline $\begin{array}{c}\text { High }(\geq 3 / \\
\geq 4^{\star} \text { diversity) }\end{array}$ & $56(31.1)$ & $\begin{array}{l}51 \\
(28.3)\end{array}$ & & $126(72.8)$ & $\begin{array}{l}62 \\
(41.6)\end{array}$ & & $110(68.8)$ & $\begin{array}{l}81 \\
(49.1)\end{array}$ & \\
\hline \multicolumn{10}{|l|}{$\begin{array}{l}\text { Food group } \\
\text { frequency }\end{array}$} \\
\hline Low (Nil) & $24(13.3)$ & $\begin{array}{l}40 \\
(22.2)\end{array}$ & 0.06 & $0(0)$ & $\begin{array}{l}11 \\
(11.6)\end{array}$ & 0.00 & $0(0)$ & $5(4.8)$ & 0.03 \\
\hline $\begin{array}{l}\text { Medium (1- } \\
2 / 1-3^{*} \text { food } \\
\text { group) }\end{array}$ & $91(50.6)$ & $\begin{array}{l}89 \\
(49.4)\end{array}$ & & $81(62.3)$ & $\begin{array}{l}55 \\
(57.9)\end{array}$ & & $85(69.1)$ & $\begin{array}{l}63 \\
(60.6)\end{array}$ & \\
\hline $\begin{array}{l}\operatorname{High}(\geq 3 / \\
\geq 4^{*} \text { food } \\
\text { group) }\end{array}$ & $65(36.1)$ & $\begin{array}{l}51 \\
(28.3)\end{array}$ & & $49(37.7)$ & $\begin{array}{l}29 \\
(30.5)\end{array}$ & & $38(30.9)$ & $\begin{array}{l}36 \\
(34.6)\end{array}$ & \\
\hline \multicolumn{10}{|l|}{$\begin{array}{l}\text { Meal frequency } \\
\text { (last } 24 \text { hours) }\end{array}$} \\
\hline $\begin{array}{l}\text { Low (no meal } \\
\text { was given) }\end{array}$ & $20(11.1)$ & $\begin{array}{l}30 \\
(16.7)\end{array}$ & & $2(1.2)$ & $1(0.7)$ & & $0(0)$ & $1(0.6)$ & \\
\hline $\begin{array}{l}\text { Medium } \\
\text { (Only single/ 1- } \\
2^{\star} \text { meal given) }\end{array}$ & $18(10)$ & $12(6.7)$ & 0.20 & $5(2.8)$ & $10(6.7)$ & 0.25 & $2(1.3)$ & $12(7.3)$ & 0.02 \\
\hline $\begin{array}{l}\operatorname{High}(\geq 2 / \\
\geq 3^{\star} \text { meals } \\
\text { given) }\end{array}$ & $142(78.9)$ & $\begin{array}{l}138 \\
(76.7)\end{array}$ & & $166(96)$ & $\begin{array}{l}138 \\
(92.6)\end{array}$ & & 158(98.8) & $\begin{array}{l}152 \\
(92.1)\end{array}$ & \\
\hline \multicolumn{10}{|l|}{ CFI score } \\
\hline Mean $( \pm S D)$ & $8.71( \pm 0.1)$ & $\begin{array}{l}8.16 \\
( \pm 0.1)\end{array}$ & 0.01 & $9.96( \pm 0.1)$ & $\begin{array}{l}9.16 \\
( \pm 0.1)\end{array}$ & 0.00 & $9.91( \pm 0.1)$ & $\begin{array}{l}9.46 \\
( \pm 0.1)\end{array}$ & 0.00 \\
\hline
\end{tabular}

Note: *9-12 months; SD: standard deviation

Distribution of components considered to compute CFI score at three time points six months, nine months and 12 months were shown in Table-4. Significant differences among the intervention and control groups had been observed for bottle feeding in three different time points. During nine months and 12 months, more than two-thirds of children had high dietary 
diversity and had medium food group frequency, which was significantly higher than the control group. However, meal frequency of babies in intervention and control groups was found significantly different in 12 months only where maximum babies had high meal frequency for both groups.

The proportion of High CFI (>=10) were persistently Higher in the intervention areas than control areas at all assessment time points. (Fig:2)

Table-5: Association between mean HAZ, WAZ, WHZ and CFI score through Generalized Estimating Equation (GEE) analysis

\begin{tabular}{|c|c|c|c|c|c|c|}
\hline \multirow{2}{*}{$\begin{array}{l}\text { CFI } \\
\text { score }\end{array}$} & \multicolumn{3}{|c|}{ Intervention; Coefficient (95\% Cl) p } & \multicolumn{3}{|c|}{ Control, Coefficient $(95 \% \mathrm{Cl}) \mathrm{p}$} \\
\hline & HAZ & WAZ & WHZ & HAZ & WAZ & WHZ \\
\hline $\begin{array}{l}\text { Model } \\
1\end{array}$ & $\begin{array}{l}0.07(0.01 \\
-0.13) 0.02\end{array}$ & $\begin{array}{l}-0.04(-0.09 \\
-0.02) 0.2\end{array}$ & $\begin{array}{l}-0.13(-0.21 \\
-0.04) 0.00\end{array}$ & $\begin{array}{l}0.04(-0.09 \\
0.16) 0.56\end{array}$ & $\begin{array}{l}-0.01(-0.15 \\
0.12) 0.86\end{array}$ & $\begin{array}{l}-0.02(-0.23 \\
0.19) 0.87\end{array}$ \\
\hline $\begin{array}{l}\text { Model } \\
2\end{array}$ & $\begin{array}{l}0.07(0.01- \\
0.13) 0.02\end{array}$ & $\begin{array}{l}-0.04(-0.09- \\
0.02) 0.2\end{array}$ & $\begin{array}{l}-0.13(-0.21 \\
-0.04) 0.00\end{array}$ & $\begin{array}{l}0.04(-0.08 \\
0.16) 0.55\end{array}$ & $\begin{array}{l}-0.01(-0.15 \\
0.12) 0.86\end{array}$ & $\begin{array}{l}-0.02(-0.23 \\
0.19) 0.88\end{array}$ \\
\hline $\begin{array}{l}\text { Model } \\
3\end{array}$ & $\begin{array}{l}0.07(0.01- \\
0.13) 0.02\end{array}$ & $\begin{array}{l}-0.04(-0.09- \\
0.02) 0.21\end{array}$ & $\begin{array}{l}-0.13(-0.21 \\
-0.04) 0.00\end{array}$ & $\begin{array}{l}0.04(-0.10 \\
0.17) 0.59\end{array}$ & $\begin{array}{l}-0.01(-0.15 \\
0.13) 0.88\end{array}$ & $\begin{array}{l}-0.02(-0.23 \\
0.19) 0.87\end{array}$ \\
\hline
\end{tabular}

Model-1: only CFl;

Model-2=Model-1 with child age and sex;

Model-3=Model-2 with maternal education, and asset score and religion.

After adjusting for potential covariates, in the final model (Table 5; Model-3), the CFI score significantly impacted a change in $\mathrm{HAZ}$ and $\mathrm{WHZ}$ over time in the intervention group. In the intervention group, for one unit change in CFI score changed the mean positive 0.07 units (increased) of child's HAZ score; negative 0.13 (decreased) units of WHZ. However, no significant change was observed in the control group.

\section{Discussion}

The present study was one of the unique educational intervention studies with an adequate sample size following a robust methodology that indicated the education improved the overall CFI index among the intervention children. Furthermore, this short-term CFI change also significantly impacted the change in HAZ score and WAZ scores among intervention children than in comparison groups.

The girls were less stunted and underweighted in intervention area than control (data not shown).

The randomly selected intervention area is outside the Matlab sub-district township, and the comparison area is within the Matlab Township. This might dilute the relationship of nutritional indices with CFI as town has an inbuilt priority to receive any public messages. In addition, during the study period, there was also a continuous national campaign on promotional messages of CF practices through mass media (radio and TV). This might contaminate the study area, but we think both the study areas had equal chances to get that information.

Considering different observation points (for example, between six and eight and nine months etc.) significant changes had been observed between the study infants. The intervention might have accelerated the growth as most of the children at this weaning stage do not consume a balanced diet mainly due to a lack of knowledge of the mothers or caregivers. On the other hand, infections and food hygiene might be another factor in addition to co-morbidities. Household food security is also found to be associated with infant and young child feeding in similar settings (25). 
Our study showed the proposed intervention for the girls had lower rates of underweight and stunting than boys, eliminating the inequity perspective if intervention strength and family's positive perception become equal irrespective of gender. Through GEE analysis this has been proved further for stunting. Thus, the CFI intervention has significant public health implications as well as policy massage. The study site, icddr,b service area, may not be ideal for this type of educational evaluation because icddr,b has been conducting many short and long-term interventions in the field of health, population and nutrition. The study design and other icddr,b facilities are critically important strengths in carrying out this evaluation study and producing highquality data and study findings. A study conducted among the Bangladeshi population in the United Kingdom found CFI is important to measure status of nutrition among children with the feeding practices, but the process is challenging to implement. The sample of this study was only 25 , which is difficult to make about the outcome of CFI (26). Another systematic review was conducted on CFI compiling the Bangladeshi population, which had three cohort, 38 cross-sectional and three mixed-method studies but not a study result following a RCT design (27). Developing CFI other than RCT designs may not be methodically robust to use in a health system. Our study is the first one in Bangladesh which has followed the highest grade design (RCT) to develop CFI which has potential for public health implications.

The strength of this study is the computed CFI has come from an RCT design probably in its first, the other available CFI has been computed mostly from the survey or hospital follow up study. This could have been shaped better through individual randomization in future studies. But, even though composite CFI score definitely has policy implications as through CFI score this is easy to understand which factors and areas are not in line with nutritional improvement to guide in evaluating am nutritional program and tell the program managers specifically which are needs to be improved for better nutritional indices.

Limitation:

This analysis is based on data from Matlab which has been criticized for not being representative of other rural areas of Bangladesh because of its many and long-term interventions in health, population and nutrition (28). Moreover, due to the non-flexibility of the data available, we might be missing some essential contextual variables during the analysis.

This study's main strengths are the quality and robustness of this randomized control data. Furthermore, the rigor of the data quality procedures and strict follow up like the study has provided a unique opportunity to produce authentic results (nearly no chances of information bias) from the analysis (29).

\section{Conclusion}

There is an immediate impact on CFI change due to short-term educational intervention that improves infantile nutrition in rural Bangladeshi infants that can be generalized due to RCT design. This intervention strategy can possibly be adapted regularly at the national level. However, a large trial with multi-site diverse locations might still be required before routine intervention policy to improve under-five child's nutrition and achieve the Sustainable Development Goal for resource-limited countries like Bangladesh.

\section{Generalizability:}

The CFI has been created through RCT, so its generated evidence is generalizable

\section{Interpretation:}

The developed CFI indicates that short term nutritional educational intervention to mother and her family member has potentiality to improve her infant nutrition status

\section{Registration:}

The registration number is NCT03024710 and date: 1/19/2017

\section{Protocol:}




\section{Declarations}

Ethics approval and consent to participate:

The Ethical Approval was obtained from Institutional Review Board (IRB) of icddr,b protocol \# PR-17087, IRB is the formal name of the ethical approval body and an informed written consent was taken from each participants before collecting data. all methods were carried out in accordance with relevant guidelines and regulations.

Consent for publication:

Informed consent was obtained from all subjects and/or their legal guardian(s).

Availability of data and materials:

Data contain potentially identifying or sensitive information from delivering women. However, "Data can be available on request". The data request should be submitted to the Research Administration (RA) of iccdr, b and will be assessed by the corresponding Ethics committee named institutional Review 351 Board of icddr, b. As a supplementary information, we have added approved protocol where you can get the study title and protocol number (PR-17087) against which data access application should be made. Please visit https://www.icddrb.org/ dmdocuments/icddrb\%20Data\%20Access\% 20Policy.pdf for additional information. Data requests are evaluated by icddr,b's Data Repository Committee (DRC) and the Research Administration (RA) serves as the Secretariat of the DRC. The key contact person of RA at present is Ms. Armana Ahmed, Lead (A), RA at aahmed@icddrb.org If the data request is considered justifiable by the DRC then RA will share the anonymous data with the applicant. Moreover, for any particular clarification of the research findings that is documented in this article, queries can be directed to the primary author of this article or to the corresponding author. Both of them can be accessed at draminur@icddrb.org. The email correspondence regarding data access could be done at the executive director office at dircetor@icddrb.org.

Competing interests:

The author reports no conflicts of interest in this work.

Funding:

The study was funded by Swedish SIDA.

Authors' contributions: AR has conceptualized and designed the study methods. AR were involved with the implementation process. AR and SKD led the data analysis, interpretation of results and development of the first draft. AR, BA and SKD contributed toward drafting and revising the paper and agree to be accountable for all aspects of the work.

Acknowledgements: The authors would also like to acknowledge the contribution of the current donors providing unrestricted support to icddr,b that include: Government of the People's Republic of Bangladesh; Global Affairs Canada (GAC), Swedish International Development Cooperation Agency (SIDA), Federation of Commonwealth Development and Organization (FCDO)

\section{References}

1. Black RE, Bhutta ZA, Alderman H, Ruel M, Gillespie S, Haddad L. Maternal and child nutrition - Authors' reply. Lancet. 2013;382(9904):1551-2. 
2. Black MM, Walker SP, Wachs TD, Ulkuer N, Gardner JM, Grantham-McGregor S, et al. Policies to reduce undernutrition include child development. Lancet. 2008;371(9611):454-5.

3. Nguyen PH, Menon P, Ruel M, Hajeebhoy N. A situational review of infant and young child feeding practices and interventions in Viet Nam. Asia Pac J Clin Nutr. 2011;20(3):359-74.

4. World Health Organization. Report of Informal Meeting to Review and Develop Indicators for Complementary Feeding. Geneva: World Health Organization; 2015.

5. Lassi ZS, Das JK, Zahid G, C. BM. Impact of education and provision of complementary feeding on growth and morbidity in children less than 2 years of age in developing countries: a systematic review. Health 13 Suppl S13. 2013;3 SRC BaiduScholar.

6. Shekar M, Heaver R, Lee Y-K. Repositioning nutrition as central to development: A strategy for large scale action: World Bank Publications; 2006.

7. Dewey KG, Adu-Afarwuah S. Systematic review of the efficacy and effectiveness of complementary feeding interventions in developing countries. Matern Child Nutr. 2008;4 Suppl 1:24-85.

8. Victora CG, de Onis M, Hallal PC, Blossner M, Shrimpton R. Worldwide timing of growth faltering: revisiting implications for interventions. Pediatrics. 2010;125(3):e473-80.

9. Jones G, Steketee RW, Black RE, Bhutta ZA, Morris SS, Bellagio Child Survival Study G. How many child deaths can we prevent this year? Lancet 2003;362(9377):65-71.

10. Asfaw M, Wondaferash M, Taha M, Dube L. Prevalence of undernutrition and associated factors among children aged between six to fifty nine months in Bule Hora district, South Ethiopia. BMC Public health. 2015;15(1):41.

11. Annan R, Webb P, Brown R. Management of moderate acute malnutrition (MAM): Current knowledge and practice. 2015.

12. Bhandari N, Mazumder S, Bahl R, Martines J, Black RE, Bhan MK, et al. An educational intervention to promote appropriate complementary feeding practices and physical growth in infants and young children in rural Haryana, India. J Nutr. 2004;134(9):2342-8.

13. Guldan GS, Fan HC, Ma X, Ni ZZ, Xiang X, Tang MZ. Culturally appropriate nutrition education improves infant feeding and growth in rural Sichuan, China. J Nutr. 2000;130(5):1204-11.

14. Santos I, Victora CG, Martines J, Gonçalves H, Gigante DP, Valle NJ, et al. Nutrition counseling increases weight gain among Brazilian children. J Nutr. 2001;131(11):2866-73.

15. Pan American Health Organization. Guiding principles for complementary feeding of breastfed child. Washington DC: Pan American Health Organization; 2003.

16. Khatoon T, Mollah MAH, Choudhury AM, Islam MM, Rahman KM. Association between infant- and child-feeding index and nutritional status: results from a cross-sectional study among children attending an urban hospital in Bangladesh. Journal of health, population, and nutrition. 2011;29(4):349-56.

17. Roy SK, Jolly SP, Shafique S, Fuchs GJ, Mahmud Z, Chakraborty B, et al. Prevention of malnutrition among young children in rural Bangladesh by a food-health-care educational intervention: a randomized, controlled trial. Food and nutrition bulletin. 2007;28(4):375-83.

18. Roy SK, Fuchs GJ, Mahmud Z, Ara G, Islam S, Shafique S, et al. Intensive nutrition education with or without supplementary feeding improves the nutritional status of moderately-malnourished children in Bangladesh. Journal of health, population, and nutrition. 2005;23(4):320-30.

19. Arimond M, Ruel MT. Dietary diversity is associated with child nutritional status: evidence from 11 demographic and health surveys. J Nutr. 2004;134(10):2579-85.

20. Ruel MT, Menon P. Child feeding practices are associated with child nutritional status in Latin America: innovative uses of the demographic and health surveys. J Nutr. 2002;132(6):1180-7.

21. Rahman A, Moran A, Pervin J, Rahman A, Rahman M, Yeasmin S, et al. Effectiveness of an integrated approach to reduce perinatal mortality: recent experiences from Matlab, Bangladesh. BMC Public Health. 2011;11:914. 
22. Mitra SN, Anne RC, Kanta J. Bangladesh Demography And Health Survey. Dhaka: National Institute of Population Research and Training; 2011.

23. Pomerleau J, Organization WH. Development of a global strategy on infant and young child feeding: report on a WHO. Copenhagen: WHO Regional Office for Europe; 2001.

24. de Onis M, Onyango AW, Borghi E, Garza C, Yang H, Group WHOMGRS. Comparison of the World Health Organization (WHO) Child Growth Standards and the National Center for Health Statistics/WHO international growth reference: implications for child health programmes. Public Health Nutr. 2006;9(7):942-7.

25. Saha KK, Frongillo EA, Alam DS, Arifeen SE, Persson LA, Rasmussen KM. Household food security is associated with growth of infants and young children in rural Bangladesh. Public health nutrition. 2009;12(9):1556-62.

26. Jabri L, Rosenthal DM, Benton L, Lakhanpaul M. Complementary feeding practices and nutrient intakes of children aged 6-24 months from Bangladeshi background living in Tower Hamlets, East London: a feasibility study. Journal of Health, Population and Nutrition. 2020;39(1):1-15.

27. Manikam L, Robinson A, Kuah JY, Vaidya HJ, Alexander EC, Miller GW, et al. A systematic review of complementary feeding practices in South Asian infants and young children: the Bangladesh perspective. BMC nutrition. 2017;3(1):56.

28. Rasheed F, Karim E. STD research and policy formulation. The Lancet. 2000;355(9211):1275.

29. Wahed T, Alam A, Sultana S, Rahman M, Alam N, Martens M, et al. Barriers to sexual and reproductive healthcare services as experienced by female sex workers and service providers in Dhaka city, Bangladesh. Plos One. 2017;12(7).

\section{Figures}

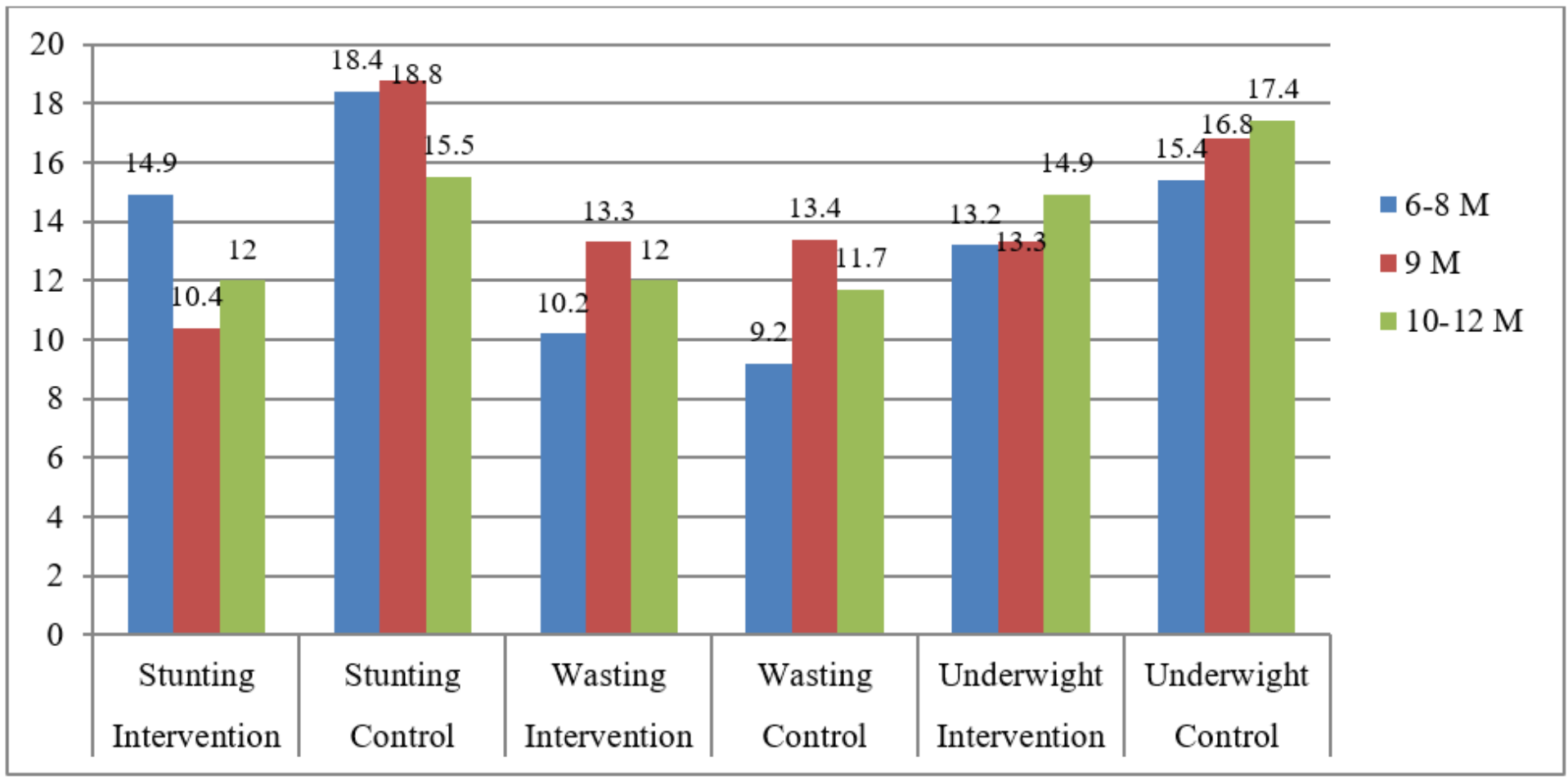

Figure 1

Proportion of nutritional indices both in intervention and control areas by different visit periods 


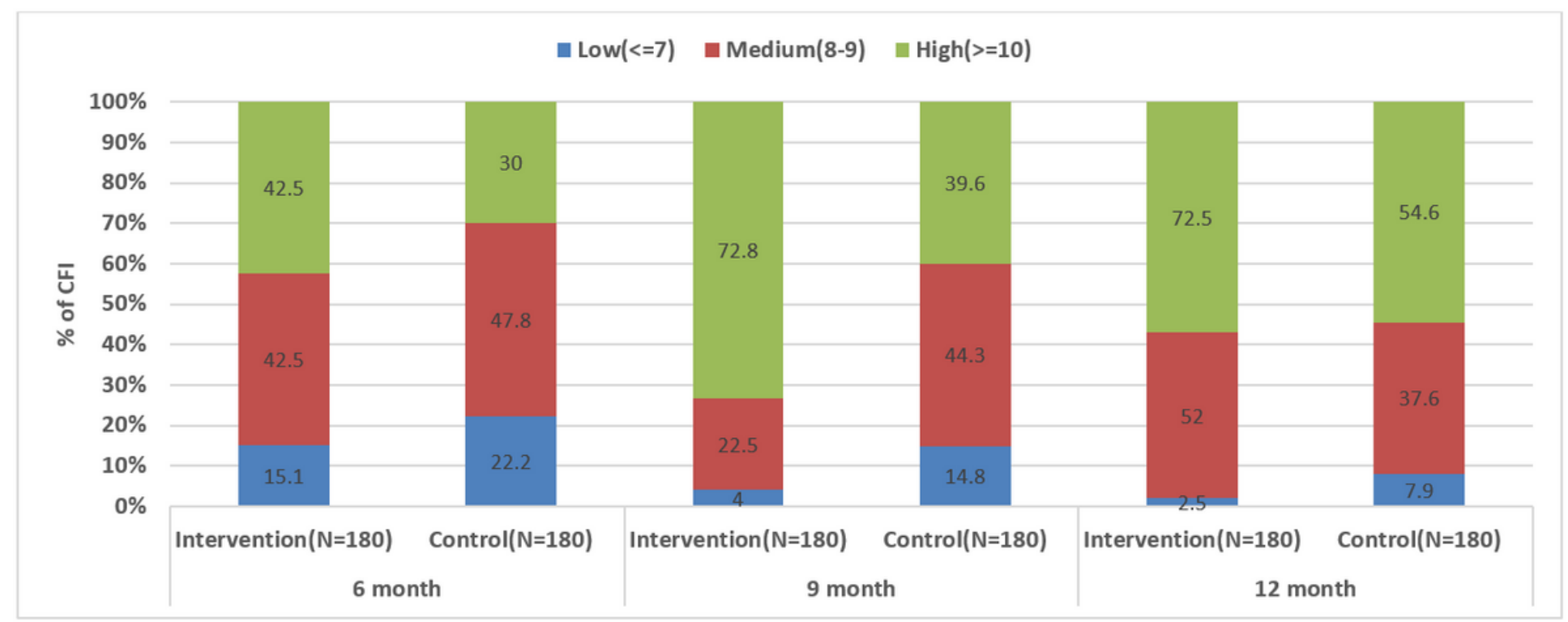

Figure 2

Proportion of Complimentary Feeding Index by categories by areas 


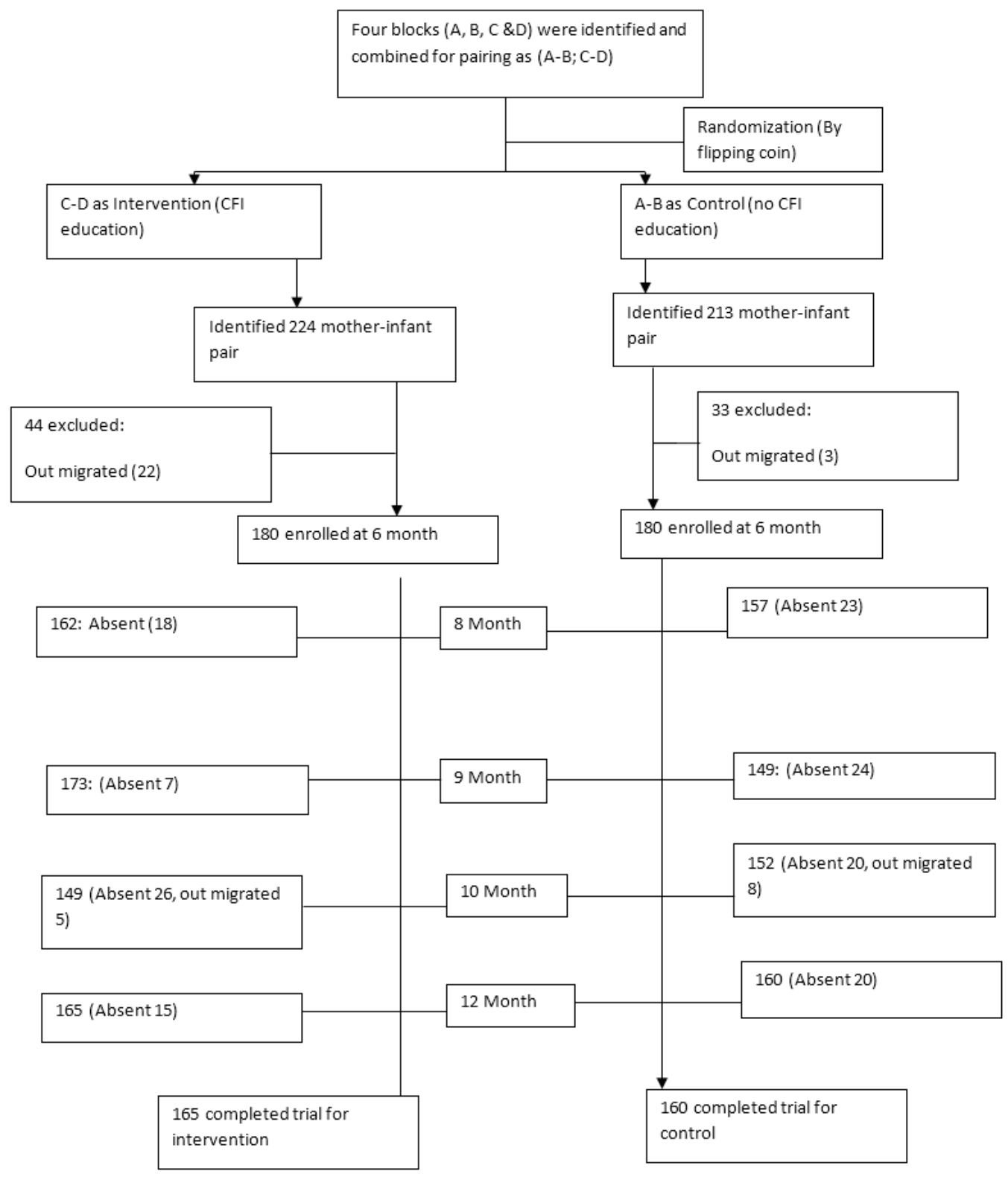

Figure 3

Trial profile 